\title{
Antifungal Activities and Preliminary Phytochemical Investigation of Combretum Species from Zimbabwe
}

\author{
Rumbidzai Mangoyi ${ }^{1}$, Washington Mafukidze ${ }^{1}$, Kerstin Marobela² and Stanley Mukanganyama ${ }^{1 *}$
}

${ }^{1}$ Biomolecular Interactions Analyses Laboratory, Department of Biochemistry, University of Zimbabwe, P.O. Box MP167, Mount Pleasant, Harare, Zimbabwe ${ }^{2}$ Department of Biological Sciences, University of Botswana, Gaborone, Botswana

\begin{abstract}
Plants used by indigenous people to produce medicines to treat different kinds of ailments maybe a source of new pharmaceuticals. The in vitro antifungal activities of six Combretum species (C. zeyheri, C. apiculatum, C. molle, C. kraussii, C. elaegnoides and C. imberbe) were investigated against Candida albicans and Candida krusei using agar disc diffusion. Broth dilution was then used to determine the minimum inhibition concentrations and minimum fungicidal concentrations of the plant extracts that had shown high efficacy against the tested microorganisms. For the plant species that had the most activity, qualitative and quantitative isolation of major phytoconstituents were determined. All extracts from the Combretum species showed antifungal activity and had MIC values ranging from $0.31 \mathrm{mg} / \mathrm{ml}-0.63 \mathrm{mg} / \mathrm{ml}$ for both Candida species. Combretum zeyheri extract had the highest antifungal activity in all cases with MIC values of 0.08 and $0.16 \mathrm{mg} / \mathrm{ml}$. Partial bioguided fractionation of $C$. zeyheri extract by sephadex LH20 gel column chromatography enabled isolation of the active fractions, fraction 3 and flavonoids. The isolated fractions were found to have drug efflux pumping inhibitory activity. Combretum species, therefore, may serve as a potential source of lead compounds that can be developed as antifungal phytomedicines. Bioactive compounds from C. zeyheri may serve as drug efflux chemo-modulators for restoring drug sensitivity to Candida cells exhibiting resistance via antifungal drug efflux.
\end{abstract}

Keywords: Candida albicans; Combretum spp; Phytoconstituents; Bioguided fractionation; Susceptibility; Drug efflux

\section{Introduction}

The search for new drugs to combat diseases and infections has become the focus of research in herbal remedies [1]. For centuries, plants have been used by indigenous people to produce medicines that were used to treat different kinds of ailments. Plants produce wide array of bioactive molecules, most of which probably evolved as chemical defense against predation or infection [2]. It is estimated that only one percent of flowering plants on earth have been studied exhaustively for their chemical composition and potential important medicinal value [3]. Large scale evaluation of the local flora exploited in traditional medicine for various biological activities is a necessary first step in the isolation and characterization of the active principle and further leading to drug development [4]. The World Health Organisation defined a medicinal plant as any herbal preparation produced by subjecting plant materials to extraction, fractionation, purification, concentration or other physical or biological process which may be produced for immediate consumption or as a basis for herbal products [5]

Many synthetic drugs owe their discovery and potency as a result of a mimic of structures from isolated natural products from plants rather than to the creativity and imagination of contemporary organic chemists [6,7]. For example, the drug taxol, (paclitaxel), one of the most powerful anticancer drug known, first isolated from the bark of the yew tree Taxus brevifolia has yielded two approved drugs for breast and ovarian cancer [8]. Several compounds including flavonoids, phenanthrenes, stilbenes, cyclobutanes and triterpenoids have been isolated from the Combretaceae species widely distributed in the tropical climes of Africa, South America and Asia. The Combretaceae species are important in traditional medical practice and some of them have been used in the treatment of syphilis, abdominal pains, conjunctivitis, diarrhoea and toothache, among other ailments $[9,10]$.

Antifungal resistance is particularly problematic as initial diagnosis of systemic fungal infection. In humans, fungal infections range from superficial to deeply invasive or disseminated, and have increased dramatically in recent years [11]. Candida albicans causes serious infections of the oral mucosa and severe oropharyngeal candidiasis afflicts many AIDS patients [12]. C. krusei is a naturally azole - resistant species which also occurs in AIDS patients or otherwise severely immunocompromised individuals [12]. Because of the resistance that pathogenic fungi build against antibiotics, there is a need for the search for new antifungal drugs from nature. Natural crude drug extracts isolated from plant species used in traditional medicine can be prolific resources for such new drugs [13]. Following previous work of screening for antifungal activity from a range of plants [14], six Combretum species used in Zimbabwe traditional medicine (C. zeyheri Sond, C. apiculatum Sond, C. molle Engl. and Diels, C. kraussii Hochst, C. elaegnoides Klotzsch and C. imberbe Wawra) were studied for their antifungal properties.

\section{Materials and Methods}

\section{Fungi and reagents}

All chemicals used in this study including nutrient agar, Sabouraud dextrose agar, miconazole, ethanol and dimethyl sulphoxide were

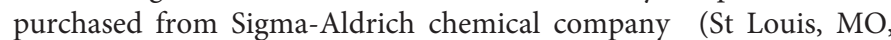
USA), and were of highest purity available. The water used for all

*Corresponding author: Dr. Stanley Mukanganyama, Department of Biochemistry University of Zimbabwe. P.O. Box MP 167 Mt. Pleasant Harare, Zimbabwe. Tel: 263-4-2917638; E-mail: smukanganyama@medic.uz.ac.zW

Received December 19, 2011; Accepted March 14, 2012; Published March 19 2012

Citation: Mangoyi R, Mafukidze W, Marobela K, Mukanganyama S (2012) Antifungal Activities and Preliminary Phytochemical Investigation of Combretum Species from Zimbabwe. J Microbial Biochem Technol 4: 037-044. doi:10.4172/1948-5948.1000069

Copyright: (c) 2012 Mangoyi R, et al. This is an open-access article distributed under the terms of the Creative Commons Attribution License, which permits unrestricted use, distribution, and reproduction in any medium, provided the original author and source are credited 
Citation: Mangoyi R, Mafukidze W, Marobela K, Mukanganyama S (2012) Antifungal Activities and Preliminary Phytochemical Investigation of Combretum Species from Zimbabwe. J Microbial Biochem Technol 4: 037-044. doi:10.4172/1948-5948.1000069

experiments was of triple distilled grade. Two different pathogenic and opportunistic fungi were used, clinical strain of Candida krusei isolated from a patient with candidiasis at Parirenyatwa Hospital was provided by Prof. V. Robertson (Department of Medical Microbiology, School of Health Sciences, Harare, Zimbabwe) and Candida albicans strain ATCC 10231, a kind gift from Dr. K. Marobela (Department of Biological Sciences, University of Botswana).

\section{Plant collection}

The plant leaves were collected from the Botanical and Herbal garden in Harare, Zimbabwe and were classified by Mr. Christopher Chapano, a taxonomist. Herbarium samples were kept at the Department of Biochemistry, University of Zimbabwe.

\section{Screening for antifungal activities of the plant species extraction}

Plant leaves were ground in a two speed blender (Cole Parmer Instrument Co., Vernon Hills, USA). Each sample was individually extracted by weighing an aliquot of $2 \mathrm{~g}$ of finely ground leaves and extracting with $10 \mathrm{ml}$ of absolute ethanol in test tubes. Extracts were filtered through fine cloth and then through $0.45 \mu \mathrm{m}$ pore size Corning syringe filters (Sigma Aldrich, Steinheim, Germany). The filtrates were decanted into pre-weighed labeled containers. The solvent was removed under a stream of air in a fume cupboard at room temperature. The amount of solid extract was weighed and recorded.

\section{Antifungal susceptibility test by the disc diffusion assay}

To determine antifungal activities of the plant extracts, cells of Candida albicans and Candida krusei were grown in nutrient broth (Oxoid Ltd, Basingstoke, Hampshire, England) for 24 hours. The cultured cells were diluted to approximately $10^{6} \mathrm{cfu} / \mathrm{mL}$ then inoculated into sterilized nutrient agar. The mixture was poured into petri dishes and gave a solid plate. The plant extracts were dissolved in absolute ethanol and $500 \mu \mathrm{g}$ of each plant extract was applied on sterile paper discs (6 $\mathrm{mm}$ diameter, cartridge susceptibility discs, Mast diagnostics, Mast Group Ltd, Merseyside, UK). The sterile paper discs were deposited on 96-well plates and ethanol was allowed to evaporate from the discs under a stream of air. The discs were then deposited on the surface of the inoculated agar plates. Miconazole (Sigma-Aldrich Chemical Co., St Louis, MO, USA) was used as positive control and ethanol and DMSO as negative controls. Plates were then incubated at $4^{\circ} \mathrm{C}$ for 2 hours and then at $37^{\circ} \mathrm{C}$, overnight. The inhibition zones which were taken as the diameter of inhibition around each of the disc.

\section{Minimum inhibitory concentration and minimum fungicidal concentration determination}

Minimum inhibition concentrations (MIC's) were determined using (3-(4,5-dimethylthiazol-2-yl)-2,5-diphenyltetrazolium bromide (MTT) assay, a colorimetric method which is used to measure the activity of enzymes that reduce MTT to formazan, giving a purple colour [15]. The plant extracts were dissolved in ethanol to a final concentration of $10 \mathrm{mg} / \mathrm{ml}$ and were serially diluted 2-fold with water in 96-well microtitre plates. Cultures of Candida species were transferred into fresh nutrient broth and $100 \mu \mathrm{l}$ of fresh culture was added to each well. Miconazole was used as the positive control and appropriate solvent blanks were included as negative control. Micro plates were incubated for 24 hours at $37^{\circ} \mathrm{C}$ and $100 \%$ relative humidity. As an indicator of growth $25 \mu \mathrm{l}$ of $2 \mathrm{mg} / \mathrm{ml}$ MTT was added to each of the microtitre plate wells and incubated for three hours. Metabolically viable cells convert the MTT into colored insoluble crystal formazan. These crystals were dissolved in dimethyl sulphoxide (DMSO) and the intensity of the purple colour formed was measured spectrophotometrically at $560 \mathrm{~nm}$. MIC was then recorded as the lowest concentration that showed no growth. The minimum fungicidal concentration (MFC) was determined by selecting concentrations of MIC values. The organisms from these wells were sub-cultured and incubated on agar for $24 \mathrm{~h}$ at $37^{\circ} \mathrm{C}$ after which they were observed for growths. The lowest concentration of the extract that showed no growth of Candida was considered as the MFC.

\section{Bioguided fractionation of C. zeyheri}

In order to isolate fractions with antifungal activity from the plant species which showed high efficacy against the tested microorganisms, the plant extract that was found to have the potent antifungal activity was fractionated by solvent-solvent partitioning then by SEPHADEX gel LH -20 column chromatography. The fractions obtained were then investigated for their antifungal activity.

\section{Extraction}

The leaves of Combretumzeyheriwere ground in a two-speed blender (Cole Parmer Instrument Co, USA) and the sample was extracted with ethanol on an orbital shaker (Bibby Scientific Limited, Staffordshire, UK) with a 4: 1 solvent to dry weight ratio for 24 hours. The extract was filtered through cotton and the filtrate was decanted into pre-weighed labeled container. The water in the extract was removed by evaporation in a vacuum rotator evaporator (Buchi Labortechnik Essen, Germany) and then weighed. The ethanol extract was further fractionated using the solvent-solvent fractionation procedure recommended by the USA National Cancer Institute as described by Suffness and Douros (1979) and adapted by Eloff (1998a). The dried ethanol extract was dissolved in $30 \%$ methanol and the partitioning was done by adding $100 \mathrm{ml}$ of the separating solvent 4 times, in order of their increasing polarity. The solvents used for partitioning were distilled petroleum ether, chloroform, ethyl acetate and butanol subsequently. All extracts were then taken to dryness in a vacuum rotator evaporator and were weighed. To determine antifungal activities of the separated fractions, the antifungal susceptibility test was carried out as indicated above.

\section{Isolation of active compounds from ethyl acetate fraction}

SEPHADEX LH-20 column chromatography is a technique which separates constituents of the extract by size, and normally used to remove unwanted substances such as chlorophyll [16]. The ethyl acetate fraction from C. zeyheri plant extract was loaded onto SEPHADEX LH-20 column chromatography (glass column, $3 \times 25 \mathrm{~cm}$ ) and separation was performed using $400 \mathrm{ml}$ of methanol:chloroform $(1: 1)$ as the solvent. The procedure was repeated three times. The fractions obtained were dried using a vacuum rotator evaporator (Buchi Labortechnik Essen, Germany) and weighed. To determine antifungal activities of the separated fractions obtained by SEPHADEX LH-20 column chromatography, the antifungal susceptibility test was carried out as explained before. Fraction 3 was found to have the most potent antifungal activity using broth dilution method, therefore, further work was done with this fraction in order to determine growth inhibition parameters.

\section{Isolation of phytoconstituents}

Phytochemical screening: The leaves of Combretum zeyheri were evaluated qualitatively and quantitatively for the determination of major phytoconstituents namely; alkaloids, flavonoids, tannins, saponins and cardiac glycosides as described by Kaur and Arora, [17]. 
Citation: Mangoyi R, Mafukidze W, Marobela K, Mukanganyama S (2012) Antifungal Activities and Preliminary Phytochemical Investigation of Combretum Species from Zimbabwe. J Microbial Biochem Technol 4: 037-044. doi:10.4172/1948-5948.1000069

\section{Qualitative screening}

Alkaloid detection was carried out by extracting powdered sample with methanol and $2 \mathrm{~N} \mathrm{HCl}$; and then treating the filtrate with Meyer's and Wagner's reagents $[18,19]$. The samples were scored positive on the basis of turbidity or precipitation. Flavonoids were tested by heating powdered sample with ethyl acetate over a steam bath (40$50^{\circ} \mathrm{C}$ ) for $5 \mathrm{~min}$; filtrate was treated with dilute ammonia. A yellow colour demonstrated a positive test for flavonoids. The presence of tannins was confirmed by boiling powdered sample in distilled water, followed by addition of drops of $5 \%$ ferric chloride $\left(\mathrm{FeCl}_{3}\right)$ to the filtrate. Development of brownish-green or blue-black colour is a positive test for the presence of tannins. Saponins content was determined by boiling powdered sample in distilled water for $15 \mathrm{~min}$ and after cooling, the extract was shaken vigorously to observe froth formation. Cardiac glycosides were identified by extracting sample in methanol. This methanolic extract was treated with glacial acetic acid containing a drop of $5 \% \mathrm{FeCl}_{3}$ solution. This solution was transferred to the surface of concentrated sulphuric acid. The formation of reddish brown ring at the junction of two liquids was indicative of cardenolides/cardiac glycosides.

\section{Bioautography of extracts}

Qualitatively isolated group of compounds were also assessed for their antifungal potential using agar disc diffusion assay. Alkaloids were isolated by mixing powdered sample with $10 \%(\mathrm{v} / \mathrm{v})$ ammonia solution and extracted with methanol for $10 \mathrm{~min}$ on water bath at $40^{\circ} \mathrm{C} \mathrm{[17].} \mathrm{The}$ mixture was then filtered through Whatman filter paper No. 1 and the filtrate was concentrated under a stream of air. Isolation of flavonoids was achieved by heating powdered sample with methanol in a water bath at $40^{\circ} \mathrm{C}$ for $10 \mathrm{~min}$. The filtrate was then concentrated to $25 \%$ of its original volume. For saponins, powdered sample was extracted with methanol by heating on a water bath at $40^{\circ} \mathrm{C}$ for $10 \mathrm{~min}$. The extract was filtered and evaporated to concentrate, mixed with water and then extracted thrice with $\mathrm{n}$-butanol. The $\mathrm{n}$-butanol phase was evaporated and concentrated. Tannins were obtained by treating powdered sample with $2 \mathrm{M}$ hydrochloric acid $(\mathrm{HCl})$ and hydrolyzing in boiling water bath for $30 \mathrm{~min}$. The solution was filtered, mixed thoroughly with ethyl acetate, and the ethyl acetate layer was then discarded. Drops of amyl alcohol were added and shaken thoroughly. The alcoholic layer was retained and used for antifungal testing. Cardiac glycosides were isolated by extracting powdered sample with $50 \%(\mathrm{v} / \mathrm{v})$ methanol and $10 \%\left(\mathrm{w} / \mathrm{v}\right.$ ) lead (II) acetate solution by heating on water bath at $40^{\circ} \mathrm{C}$ for $10 \mathrm{~min}$. The filtrate was cooled to room temperature and then extracted twice with dichloromethane/isopropanol (3:2) solution. The combined lower phases were filtered over anhydrous sodium sulphate and evaporated to dryness. The residue was dissolved in dichloromethane/ isopropanol (3:2) and this solution was further used for antifungal investigations. The five isolated groups of compounds were applied on sterile paper discs (6 $\mathrm{mm}$ diameter, cartridge susceptibility discs, Mast diagnostics, Mast Group Ltd, Merseyside, UK) and the discs were then air-dried and used for antifungal activity testing.

\section{Quantitative analysis}

Alkaloids were quantitatively determined according to the method of Harborne [20], Acetic acid (10\%) in ethanol was added to powdered sample, covered and allowed to stand for $4 \mathrm{~h}$. The filtrate was then concentrated on a water bath to $25 \%$ of its original volume. Concentrated ammonium hydroxide was added drop wise to the extract until the precipitation was complete. The whole solution was allowed to settle; collected precipitates were washed with dilute ammonium hydroxide and then filtered. The residue was dried, weighed and expressed as the alkaloids.

To estimate flavonoids quantitatively, powdered sample was extracted twice with $80 \%$ aqueous methanol at room temperature. The solution was filtered through Whatman filter paper No.1, the filtrate was later transferred into crucibles, evaporated to dryness on a water bath to a constant weight.

Quantitative determination of saponins was done according to Obadoni and Ochuko, [21]. Twenty grams of each powdered sample was added to $20 \%$ aqueous ethanol and kept in a shaker for $30 \mathrm{~min}$. The samples were heated over a water bath for $4 \mathrm{~h}$ at $55^{\circ} \mathrm{C}$. The mixture was then filtered and the residue re-extracted with another $20 \%$ aqueous ethanol. The combined extracts were reduced over water bath at $90^{\circ} \mathrm{C}$ The concentrate was then extracted twice with diethyl ether. Ether layer was discarded while aqueous layer was retained and n-butanol was added to it. Then n-butanol extracts were washed twice with 5\% aqueous sodium chloride. The remaining solution was heated in a water bath and after evaporation the samples were dried in oven at $40^{\circ} \mathrm{C}$ to a constant weight. The saponin content was calculated as percentage of the initial weight of sample taken.

Determination of tannin content was performed according to the method of Van-Burden and Robinson [22], with some modifications. Distilled water was added to the sample, taken in a $500 \mathrm{ml}$ flask and kept in shaken for $1 \mathrm{~h}$. It was filtered into a $50 \mathrm{ml}$ volumetric flask and made up to the mark. The filtrate was then dispensed into a test tube and mixed with $0.1 \mathrm{M} \mathrm{FeCl}_{3}$ in $0.1 \mathrm{~N} \mathrm{HCl}$ and $0.008 \mathrm{M}$ potassium ferrocyanide. Absorbance was measured at $605 \mathrm{~nm}$ within $10 \mathrm{~min}$.

\section{Drug accumulation and efflux assays}

The concept of parameter $\mathrm{IC}_{50}$ is fundamental to pharmacology. It is the concentration of an inhibitor where the response to an effector is reduced by half. In this study, $\mathrm{IC}_{50}$ was determined in order to measure the effectiveness of $C$. zeyheri fractions as drug efflux pump inhibitors. This was done by measuring the accumulation of ciprofloxacin in the Candida species. Fungi were grown in nutrient broth (NB) at $37^{\circ} \mathrm{C}$ to an $\mathrm{A}_{660}$ of $0.6-0.8$ and harvested by centrifugation at $8000 \mathrm{r} / \mathrm{min}$ for 5 minutes. Fungi were then washed once with $50 \mathrm{nmol} / \mathrm{L}$ sodium phosphate buffer ( $\mathrm{pH} \mathrm{7.0)}$ at $4^{\circ} \mathrm{C}$ and resuspended in the same buffer at about $40 \mathrm{mg}$ (dry weight) cells $/ \mathrm{ml}$. The cells were placed in a water bath set at $37^{\circ} \mathrm{C}$ for 15 minutes. Cells were then split into aliquots of 1.5 $\mathrm{ml}$ and maintained at the same temperature. Ciprofloxacin was added to cells to a final concentration of $0.02 \mathrm{mg} / \mathrm{ml}$. The plant extracts were then added to all the tubes to a final concentration of $0-0.1 \mathrm{mg} / \mathrm{ml}$. The concentrations of the plant extracts were prepared by 2.5 fold serial dilution. Aliquots of $750 \mu \mathrm{L}$ cells were removed at 60 minutes after the addition of ciprofloxacin to the fungi from all microtubes. Cells were diluted immediately into $750 \mu \mathrm{L}$ chilled sodium phosphate buffer ( $\mathrm{pH}$ 7.0) on ice, and then centrifuged in a micro centrifuge (Hermle Labortechnik, Steinheim, Germany) at $8000 \mathrm{r} / \mathrm{min}$, at $4^{\circ} \mathrm{C}$ for 5 minutes. The fungi were washed again in the chilled buffer and re-centrifuged for 5 minutes. The cell pellet was suspended in $3.0 \mathrm{ml}$ glycine hydrochloride $(0.1 \mathrm{~mol} / \mathrm{L}, \mathrm{pH} 3.0)$ for 2 hours at $30^{\circ} \mathrm{C}$, and centrifuged at $8000 \mathrm{r} / \mathrm{min}$ for 10 minutes. The supernatant was centrifuged for another 5 minutes. The active efflux of ciprofloxacin was determined at the excitation and emission wavelengths of $270 \mathrm{~nm}$ and $452 \mathrm{~nm}$ respectively using an RF1501 Shimadzu Spectrofluoremeter (Shimadzu Cooperation, Tokyo, Japan). 
Citation: Mangoyi R, Mafukidze W, Marobela K, Mukanganyama S (2012) Antifungal Activities and Preliminary Phytochemical Investigation of Combretum Species from Zimbabwe. J Microbial Biochem Technol 4: 037-044. doi:10.4172/1948-5948.1000069

\section{Results}

\section{Disk diffusion assay}

The inhibitory activity of six Combretum plant extracts against Candida albicans and Candida krusei are shown in Table 1. All of the six plant extracts tested were active against Candida albicans by disc diffusion assay, with zones of inhibition varying from 7 to 18.5 $\mathrm{mm}$, and only four were active against $C$. krusei. The ethanol extracts of leaves of Combretum zeyheri, Combretum imberbe, Combretum apiculatum and Combretum elaegnoides, showed significant antifungal effects against Candida albicans and Candida krusei. Combretum molle and Combretum kraussi extracts showed mild antifungal activity against C. albicans and no activity against C. krusei. Miconazole at a concentration of $10 \mathrm{mg} / \mathrm{ml}$ was used as a positive control while ethanol was used as a negative control. Dimethylsulfoxide was also tested to rule out the effect of the solvent.

All the five fractions obtained (Figure 1) by solvent-solvent

\begin{tabular}{|c|c|c|c|c|c|c|}
\hline \multirow[b]{2}{*}{ Family } & \multicolumn{2}{|l|}{ Plant material (crude extract) } & \multirow[b]{2}{*}{ Part used } & \multicolumn{2}{|c|}{ Zone of inhibition (mm) } & \multirow[b]{2}{*}{ Ethnomedicinal information } \\
\hline & Scientific & Local & & Candida albicans & Candida krusei & \\
\hline Combretaceae & $\begin{array}{l}\text { Combretum molle } \\
\text { Engl. \& Diels }\end{array}$ & Mudziyaishe & leaves & $7.7 \pm 0.7$ & 6 & $\begin{array}{l}\text { Used medicinally to treat fever and stomach } \\
\text { complaints }\end{array}$ \\
\hline Combretaceae & Combretum imberbe Wawra & Muchenarota, Monzo & leaves & $15.5 \pm 0.5$ & $16.2 \pm 0.2$ & $\begin{array}{l}\text { Coughs. Colds, diarrhoea (Rogers and Verotta, } \\
\text { 1996) }\end{array}$ \\
\hline Combretaceae & $\begin{array}{l}\text { Combretum apiculatum } \\
\text { Sond }\end{array}$ & $\begin{array}{l}\text { Chikukute, } \\
\text { Mugodo, Bonda }\end{array}$ & leaves & $10.0 \pm 0.1$ & $10.3 \pm 0.6$ & $\begin{array}{l}\text { Snake and scorpion bite, bloody diarrhoea, } \\
\text { leprosy, abdominal disorders, conjuctivities and } \\
\text { weak body. (Rogers and Verotta, } 1996\end{array}$ \\
\hline Combretaceae & $\begin{array}{l}\text { Combretum zeyheri } \\
\text { Sond }\end{array}$ & $\begin{array}{l}\text { Muruka, mupembere- } \\
\text { kono, muchenja }\end{array}$ & leaves & $18.5 \pm 0.5$ & $18.0 \pm 0.3$ & $\begin{array}{l}\text { Coughs, diarrhoea, rectal prolapse, Snake bites } \\
\text { and stomachache (Ruffo,1991) }\end{array}$ \\
\hline Combretaceae & $\begin{array}{l}\text { Combretum elaegnoides } \\
\text { Klotzsch }\end{array}$ & Muswati, Mukapo & leaves & $12.20 \pm 0.7$ & $11.4 \pm 0.3$ & - \\
\hline \multirow[t]{4}{*}{ Combretaceae } & Combretum kraussii Hochst & - & leaves & $7 \pm 0.8$ & 6 & $\begin{array}{l}\text { Antidiuretics, lotions for eye infections, as well as } \\
\text { antiseptics }\end{array}$ \\
\hline & Miconazole & & & $15.5 \pm 0.5$ & $14.4 \pm 0.7$ & \\
\hline & Dimethylsufoxide (DMSO) & & & 6 & 6 & \\
\hline & Ethanol & & & 6 & 6 & \\
\hline
\end{tabular}

${ }^{a}$ Results are the average $( \pm S D$ ) of two separate antifungal susceptibility test (Each antifungal susceptibility test was followed by a disk diffusion assay done in quadruplicate at $500 \mu \mathrm{g}$ of sample per disk). Miconazole was used as a positive control and DMSO and ethanol were used as negative controls

Table 1: Antifungal activity of plant extracts by the agar disc diffusion method.

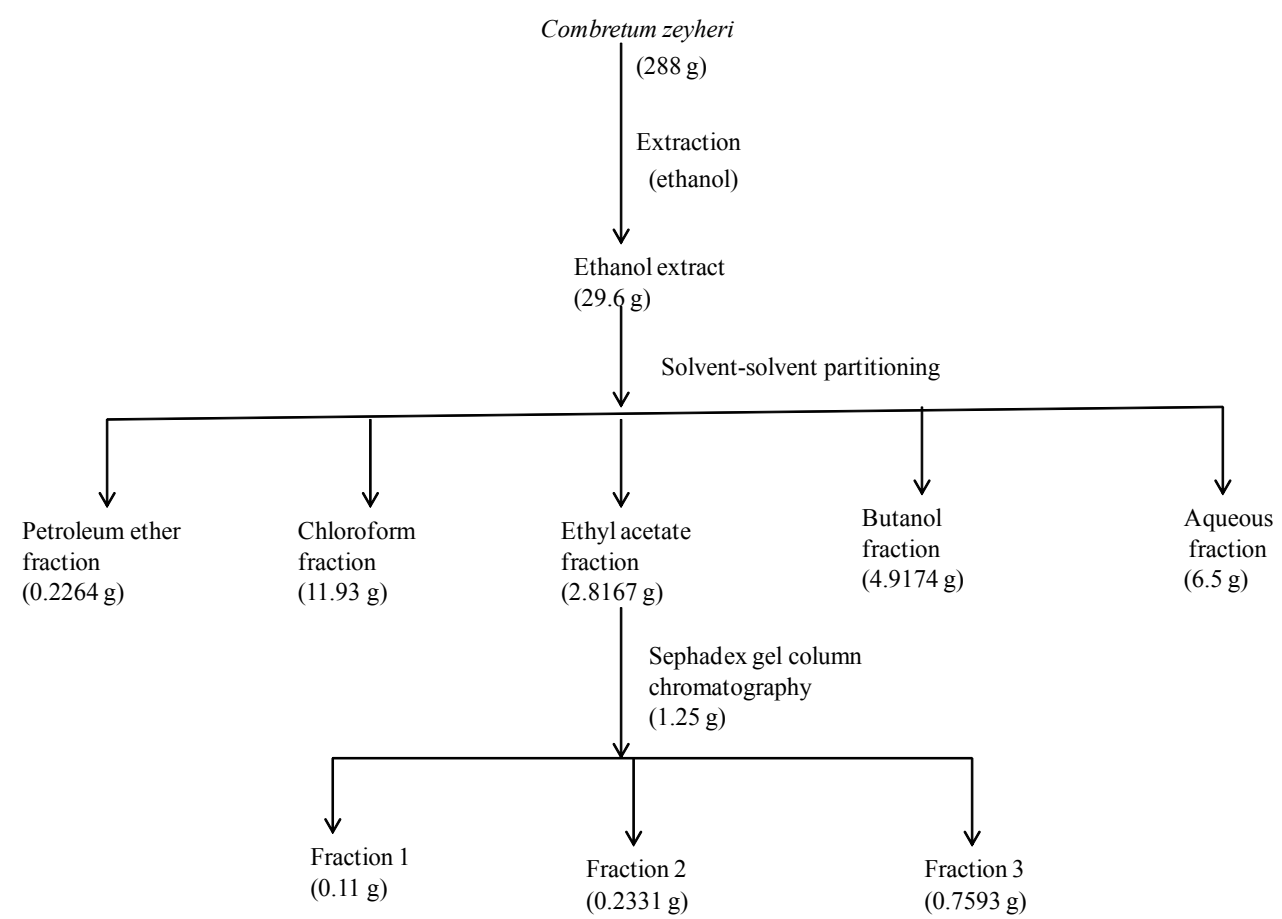

Figure 1: Constituencies of $C$. zeyheri ethanolic extract separated according to their polarity. The ethanol extract of $C$. zeyheri was separated by solvent - solvent partitioning using different solvents. The constituencies in ethyl acetate fraction were further separated by SEPHADEX gel column chromatography. 
Citation: Mangoyi R, Mafukidze W, Marobela K, Mukanganyama S (2012) Antifungal Activities and Preliminary Phytochemical Investigation of Combretum Species from Zimbabwe. J Microbial Biochem Technol 4: 037-044. doi:10.4172/1948-5948.1000069

partitioning were tested for their antifungal activity against $C$. albicans and C. krusei and results are shown in Table 3. The ethyl acetate fraction had the highest antifungal activity against both Candida species tested. The results obtained with ethyl acetate fraction were comparable with those obtained with the standard antifungal drug, miconazole. No activity was found in the aqueous extract. Constituencies of the ethyl acetate fraction separated by SEPHADEX LH-20 gel column chromatography were also tested for their antifungal activity and results are shown in Table 4 . The results show that fractions 3 had the highest antifungal activity as compared to all the fractions tested. Combretum zeyheri phytoconstituents, alkaloids and saponins also demonstrated their antifungal effect against Candida species (Table 6) while tannins and flavonoids did not show inhibitory activity. This study shows that the

\begin{tabular}{|l|l|l|l|l|}
\hline Plant species & C. albicans & & C. krusei & \\
& MIC & MFC & MIC & MFC \\
\hline Combretum zeyheri & 0.08 & 0.31 & 0.16 & 0.63 \\
Combretum imberbe & 0.31 & 0.63 & 0.63 & 1.25 \\
Combretum apiculatum & 0.31 & 0.31 & 0.63 & 0.63 \\
Combretum elaeagnoides & 0.31 & $>10$ & 0.63 & $>10$ \\
Miconazole & 1.25 & 1.25 & 1.25 & 1.25 \\
\hline
\end{tabular}

All results are the average ( \pm SD) of two separate MTT assays and are in $\mathrm{mg} / \mathrm{ml}$ Table 2: Minimum inhibitory concentrations and minimum fungicidal concentrations of different Combretum extracts.

\begin{tabular}{|l|c|c|}
\hline & C. albicans & C. krusei \\
\hline Fraction & \multicolumn{2}{|c|}{${ }^{\text {bZone of Inhibition }(\mathrm{mm})}$} \\
\hline Petroleum ether & $8 \pm 0.1$ & $10 \pm 1.2$ \\
\hline Chloroform & $10 \pm 0.2$ & $12 \pm 1.8$ \\
\hline Ethyl acetate & $11 \pm 0.8$ & $21 \pm 1.8$ \\
\hline Butanol & $10 \pm 0.3$ & $20 \pm 0.8$ \\
\hline Aqueous & 6 & 6 \\
\hline Ethanol & 6 & 6 \\
\hline Miconazole & $15 \pm 1.1$ & $22 \pm 1.4$ \\
\hline
\end{tabular}

${ }^{b}$ Results are the average $( \pm S D$ ) of two separate antifungal susceptibility test (Each antifungal susceptibility test was followed by a disk diffusion assay done in quadruplicate at $500 \mu \mathrm{g}$ of sample per disk. Ethanol was used as the negative control and miconazole as the positive control.

Table 3: Effect of fractions from C. zeyheri extract on C. albicans and C. krusei.

\begin{tabular}{|l|c|c|}
\hline \multicolumn{3}{|c|}{${ }^{\circ}$ Zone of inhibition $(\mathrm{mm})$} \\
\hline Fraction & C. albicans & C. krusei \\
\hline 1 & $12 \pm 0.7$ & $11 \pm 0.3$ \\
\hline 2 & $12 \pm 0.3$ & $12 \pm 0.6$ \\
\hline 3 & $15 \pm 1.0$ & $15 \pm 1.4$ \\
\hline Ethanol & $6 \pm 0$ & $6 \pm 0$ \\
\hline Miconazole & $15 \pm 1.2$ & $17 \pm 1.8$ \\
\hline
\end{tabular}

"Results are the average ( $\pm S D$ ) of two separate antifungal susceptibility test (Each antifungal susceptibility test was followed by a disk diffusion assay done in quadruplicate AT $500 \mu \mathrm{g}$ of sample per disk). Ethanol was used as the negative control since all the tested samples were dissolved in ethanol, and miconazole as the positive control

Table 4: Effect of fractions separated by Sephadex column chromatography on C. albicans and C. krusei.

\begin{tabular}{|l|l|l|l|l|}
\hline Plant name & $\begin{array}{l}\text { C. albicans } \\
\text { MIC }\end{array}$ & MFC & MIC & MFC \\
\hline Combretum zeyheri & & & & \\
Ethanol extract & 0.08 & 0.31 & 0.16 & 0.63 \\
Fraction 3 & 0.31 & 1.25 & 2.5 & 2.5 \\
Miconazole & 1.25 & 1.25 & 1.25 & 1.25 \\
\hline
\end{tabular}

"All results are the average ( \pm SD) of two separate MTT assays and are in $\mathrm{mg} / \mathrm{ml}$ Table 5: MICs and MFCs of ethanol crude extract and fraction 3 of $C$. zeyheri against $C$. albicans and C. krusei.

\begin{tabular}{|l|l|l|l|}
\hline & & $\begin{array}{l}\text { dZone of Inhibition } \\
(\mathrm{mm})\end{array}$ & \\
\hline Phytoconstituencies & $\begin{array}{l}\text { Percentage yield in } \\
\text { plant \% }\end{array}$ & C. albicans & \multicolumn{1}{|c|}{ C. krusei } \\
\hline Flavonoids & 2.3 & $10 \pm 0.1$ & $9 \pm 0.9$ \\
\hline Alkaloids & 1.08 & $9 \pm 0.3$ & $9 \pm 0.2$ \\
\hline Saponins & 0.8 & $8 \pm 0.1$ & $7 \pm 0.3$ \\
\hline Tannins & 21.5 & 6 & 6 \\
\hline Cardiac glycosides & ND & 6 & 6 \\
\hline DMSO & & 6 & 6 \\
\hline Ethanol & & 6 & 6 \\
\hline Miconazole & $14 \pm 0.2$ & $14 \pm 1.6$ \\
\hline
\end{tabular}

${ }^{d}$ Results are the average ( \pm SD) of two separate antifungal susceptibility test (Each antifungal susceptibility test was followed by a disk diffusion assay done in quadruplicate). Ethanol was used as the negative control and miconazole as the positive control

The percentage yield was calculated using the formula below

Percentage yield $(\%)=\frac{\text { Mass of powdered plant extract }(\mathrm{g})}{\text { Mass of plant material }(\mathrm{g})} \times 100$

Table 6: Phytochemical evaluation of leaves of $C$. zeyheri and effect of these

phytoconstituents on C. albicans and C. krusei.

crude extracts contain a number of phytoconstituents whose isolation and purification may yield significant novel antimicrobial agents. However, C. zeyheri crude extract exhibited better activity in terms of zone of inhibition relative to its fractions and phytoconstituents.

\section{MICs and MFCs of plant extracts}

The four plant extracts of Combretum zeyheri, Combretum imberbe, Combretum apiculatum and Combretum elaeagnoides, which showed a significant antifungal activity, comparable to the antifungal activity of miconazole against both Candida species, were selected further for determination of their minimum inhibition concentrations (MIC) and their minimum fungicidal concentrations (MFC) using the broth dilution method. Table 2 shows the MICs and MFCs of the plant extracts against Candida albicans and Candida krusei. MIC values ranged from $0.31 \mathrm{mg} / \mathrm{ml}-0.63 \mathrm{mg} / \mathrm{ml}$ for both Candida albicans and Candida krusei. Combretum zeyheri plant extract had the most antifungal activity as shown in the table, with an MIC of $0.08 \mathrm{mg} / \mathrm{ml}$ against $C$. albicans and $0.31 \mathrm{mg} / \mathrm{ml}$ against $C$. krusei.

Further work was done to determine the MIC of C. zeyheri fraction 3 and then compare with the MIC of the crude extract. The results show that $C$. zeyheri, fraction 3 had a higher MIC against C. albicans than the crude extract. The MFC of the fraction 3 was also determined using broth dilution method and results recorded in Table 5 . 
Citation: Mangoyi R, Mafukidze W, Marobela K, Mukanganyama S (2012) Antifungal Activities and Preliminary Phytochemical Investigation of Combretum Species from Zimbabwe. J Microbial Biochem Technol 4: 037-044. doi:10.4172/1948-5948.1000069

\section{Qualitative and quantitative analysis of leaves for their phytoconstituents}

Qualitative phytochemical analysis of C. zeyheri showed the presence of alkaloids, flavonoids, tannins, saponins and cardiac glycosides and the data for their quantitative determination is shown in Table 6.

\section{Plant extracts as efflux pump inhibitors}

Combretum zeyheri ethanol extract, fraction 3 and flavonoids were able to act as inhibitors of drug efflux pumps in Candida species, results shown in Figure 2. Fraction 3 of Combretum zeyheri was the most potent as it reduced the activity of the drug efflux pumps in Candida albicans by $50 \%$ at $0.73 \mu \mathrm{g} / \mathrm{ml}$ while crude ethanolic extract reduced it at $1.4 \mu \mathrm{g} / \mathrm{ml}$. Reserpine, a standard drug efflux inhibitor reduced activity of the efflux pumps in C. albicans by $50 \%$ at $0.1 \mathrm{mg} / \mathrm{ml}$.

\section{Discussion}

In the past two decades, the prevalence of life-threatening infections has increased significantly [23]. Among them, candidiasis is the most frequently fungal infection causing morbidity in seriously debilitated and immunocompromised hosts [24]. Although a large number of antimicrobial agents have been discovered, pathogenic microorganisms are constantly developing resistance to these agents $[25,26]$. In recent years, attempts have been made to investigate the indigenous drugs against infectious diseases in order to help developing safer antimicrobial drugs $[26,27]$.

The present study showed that four Combretum plant extracts had profound antifungal effects against Candida albicans and Candida krusei when compared with the positive control, miconazole and, therefore, may have potential use as antifungal agents. MIC and MFC results showed that Combretum zeyheri and Combretum apiculatum plant extracts had the ability to kill fungal cells at a very low concentration as compared to all the tested plant extracts and the standard inhibitor miconazole (Table 2). This fungicidal activity gives credit to these plants as traditional medicine for treatment of different ailments [28]. A number of antibacterial compounds including flavonoids (apigenin; genkwanin; 5-hydroxy-7,4'-dimethoxyflavone, rhamnocitrin; kaempferol; quercetin-5,3'-dimethylether; rhamnazin ) were isolated from Combretum species [10]. Martini and Eloff (1998) demonstrated the presence of at least 14 different unidentified bacterial inhibitors, of widely differing polarity, in leaves of Combretum erythrophyllum. MacGaw et al. [29], have investigated some of the biological activity which include anti-inflammatory, anthelmintic, antischistosomal and DNA-damaging effects of Combretum species. Significant activity in more than one bioassay was exhibited by $C$. apiculatum, $C$. hereroense, C. molle and C. mossambicense. Breytenbach and Malan [30], isolated three antibacterial compounds from Combretum zeyheri and proposed structures for two of them.

Fractionation of C. zeyheri extract by solvent-solvent partition produced fractions that had antifungal activity and of these the ethyl acetate fraction was found to have the most antifungal effects when compared with the positive control, miconazole (Table 3 ). These results show that ethyl acetate was able to extract the compounds with most antifungal activity and these could be flavonoids since they have been previously reported to have antifungal effects. Most antifungal constituents were extracted in intermediate polarity solvent (ethyl acetate), fewer in high (butanol) and least in low polarity (petroleum ether and chloroform). However, compared to the activity of the crude extracts, the antifungal
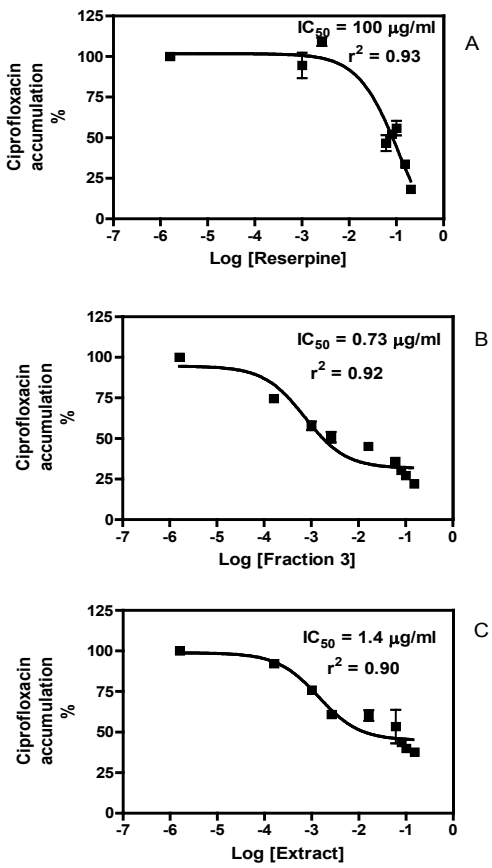

Figure 2: Effects of C. zeyheri extract, Fraction 3 and reserpine on $C$. albicans efflux pumps. Fraction 3 and $C$. zeyheri extract were able to reduce the activity of the drug efflux pumps in C. albicans by $50 \%$ at $0.73 \mu \mathrm{g} / \mathrm{ml}$ and $1.4 \mu \mathrm{g} / \mathrm{m}$ respectively.

activity of fractions obtained by solvent-solvent partition was less potent and this could be due to loss of active compounds during fractionation. Further fractionation of the ethyl acetate extract was performed by a SEPHADEX LH-20 gel filtration to give three major constituents namely fraction 1, fraction 2 and fraction 3 . The antifungal activities of these three constituents were determined by a dilution assay and of these, fraction 3 inhibited growths of $C$. albicans and C. krusei with MIC values of 0.31 and $2.5 \mathrm{mg} / \mathrm{ml}$ respectively (Table 5). These results are a general agreement to the published literature, where Combretum zeyheri fractions isolated by bioassay-guided fractionation are known to have potent antimicrobial activity [31].

Combretum zeyheri plant extract was subjected to various phytochemical tests to identify the chemical constituents present and the results showed the presence of flavonoids, saponins, alkaloids, cardiac glycosides and tannins. Of these phytoconstituents, flavonoids were found to have the most antifungal activity. Previously, flavonoids have been reported to posses antimicrobial activity [32]. It has been reported that the antimicrobial activity of flavonoids is due to their ability to complex with extracellular and soluble protein and to complex with fungal cell [33]. The results of antifungal activity against Candida albicans and Candida krussei have indicated that ethanol extract of C. zeyheri was found to be significantly active exhibiting the highest potency with MICs of. 0.08 and $0.16 \mathrm{mg} / \mathrm{ml}$ respectively. This activity may be attributed to the rich flavonoids content of the plant.

Overexpression of multi-drug efflux transporters, including ABC transporters, has been shown to be a major mechanism for the drug resistance for Candida species [34]. Among ABC transporters, Cdrlp and Cdr2p have been reported as major drug efflux pump proteins, which play a key role in azole resistance of Candida species [35] Mukhopadhyay et al. [36], examined the functionality of Cdrlp drug extrusion pump by measuring the efflux of rhodamine (R6G), a known 
Citation: Mangoyi R, Mafukidze W, Marobela K, Mukanganyama S (2012) Antifungal Activities and Preliminary Phytochemical Investigation of Combretum Species from Zimbabwe. J Microbial Biochem Technol 4: 037-044. doi:10.4172/1948-5948.1000069

substrate of Cdr1p and similarly, R6G was used as the substrate of efflux pumps in this study. The results of the study show that the whole extract and fraction 3 of C. zeyheri had inhibitory effects on drug efflux to an extent that was significantly higher than reserpine. R6G has been reported to be a substrate of drug efflux pumps in Candida [12], and this was also shown in this study. Other studies have show that ciprofloxacin is a substrate for bacterial ATP-dependent efflux pumps $[37,38]$. This study also shows that ciprofloxacin is a substrate of ATPdependent drug efflux pumps in Candida. The inhibition of drug efflux transporters in C. albicans would be expected to restore azole sensitivity to drug resistant forms of Candida albicans whose mechanism of azole resistance is via drug efflux. The results of the present study provide a pharmacological basis for the traditional use of Combretum species for infectious diseases especially in therapeutic applications against fungal infections. These results may also confirm the great potential of plants of the Zimbabwe ethnomedicine for production of bioactive compounds. Further investigations on isolation and characterization of antifungal bioactive agents from these plants are in progress. It is also necessary to determine the composition of fraction 3 from C. zeyheri.

\section{Conclusion}

Combretum species are a source of bioactive antifungal compounds. Combretum zeyheri was found to have the most potent antifungal activity and some of its fractions isolated were also found to have antifungal activity and to reduce the activity of Candida albicans efflux pumps. However, C. zeyheri crude extract exhibited better activity in terms of zone of inhibition relative to its fractions and phytoconstituents. This study has identified C. zeyheri plant as a plant with potential antifungal activity and partial isolation of active agents has shown that it can be used as a source for the isolation of active compounds that may serve as lead compounds in antifungal drug development.

\section{References}

1. Chokoe PK, Masoko P, Mokgotho MP, Howard RL, Mampuru LJ (2008) Does seasonal variation influence the phytochemical and antibacterial properties of Carpobrotus edulis? Afr J Biotechnol 7: 4164-4171

2. Samie A, Tambani T, Harshfield E, Green E, Ramalivhana JN, et al. (2010) Antifungal activities of selected Venda medicinal plants against Candida albicans, Candida krusei and Cryptococcus neoformans isolated from South African AIDS patients. Afr J Biotech 9: 2965-2976.

3. Farhana AR, Nahar L, Haque M, Islam MM, (2009) Antibacterial Cytotoxic and Antioxidant Activity of Crude Extract of Marsilea Quadrifolia. Europ J Sci Res 33: $123-129$

4. Xiang L, Zhi L, Xin-feng Z, Li-juan W, Yi-nan Z, et al. (2008) Isolation and Characterization of Phenolic Compounds from the Leaves of Salix matsudana. Molec 13: 1530-1537.

5. (2000) General Guidelines for Methodologies on Research and Evaluation of Traditional Medicine. WHO, Geneva

6. Zarrin M, Jamshidian M, Jafari M (2009) In vitro interactions of miconazole with sulfametoxazole against Candida species. Pak J Med Sci 25: 243-246.

7. Jagessar RC, Mars A, Gomathinayagam S (2011) Selective Antimicrobial properties of Leaf extract of Samanea Saman against Candida albicans, Staphylococcus aureus and Escherichia coli using several microbial methods. J American Sci 7: 3

8. Jagessar RC, Mars A, Gomes G (2008) Selective Antimicrobial properties of Phyllanthus acidus leaf extract against Candida albicans, Escherichia coli and Staphylococcus aureus using Stokes Disc diffusion, Well diffusion, Streak plate and a dilution method. Nat and Sci 6: 24-38

9. Masoko P, Eloff JN (2006) Bioautography indicates the multiplicity of antifungal compounds from twenty-four southern African Combretum species (Combretaceae). Afr J Biotech 5: 1625-1647.
10. Martini ND, Katerere DRP, Eloff JN (2004) Biological activity of five antibacterial flavonoids from Combretum erythrophyllum (Combretaceae). J Ethnopharmacol 93: 207-212.

11. Al-Fatimi M, Wurster M, Schroder G, Lindequist U (2007) Antioxidant, antimicrobial and cytotoxic activities of selected medicinal plants from Yemen. J Ethnopharmacol 111: 657-666.

12. Cannon RD, Lamping E, Holmes AR, Niimi K, Baret PV, (2009) Efflux mediated antifungal drug resistance. Clin Microbiol Rev 22: 291-321.

13. Kayembe JS, Taba KM, Ntumba K, Tshiongo MTC, Kazadi TK (2010) In vitro anti-malarial activity of 20 quinones isolated from four plants used by traditional healers in the Democratic Republic of Congo. J Med Plants Res 4: 991-994.

14. Mangoyi R, Mukanganyama S (2011) In Vitro Antifungal Activities of Selected Medicinal Plants from Zimbabwe against Candida albicans and Candida krusei. African J Plant Sci Biotech 8-14.

15. Arun T, Rabeeth M, (2010) Genotoxic effect of paracetamol containing tablets in cultured human lymphocytes. Int J Biomed Res 1: 21-30.

16. Dai J, Mumper RJ (2010) Plant Phenolics: Extraction, Analysis and Their Antioxidant and Anticancer Properties. Mol 15: 7313-7352.

17. Kaur GJ, Arora DS (2009) Antibacterial and phytochemical screening of Anethum graveolens, Foeniculum vulgare and Trachyspermum ammi. BMC Complem Alter Med 9: 30.

18. Oyedapo OO, Sab FC, Olagunju JA (1999) Bioactivity of fresh leaves of Lantana camara. Biomed Letters 59: 175-183.

19. Sofowora EA (1993) Phytochemical Assays In "Medicinal Plants and Traditiona Medicine in Africa". 3rd Edition Spectrum Books Limited Nigeria pp 150- 153.

20. Harborne JB (2005) Phytochemical methods-A guide to modern techniques of plant analysis. Springer Pvt Ltd.

21. Obadoni BO, Ochuko PO (2001) Phytochemical studies and comparative efficacy of the crude extracts of some Homostatic plants in Edo and Delta States of Nigeria. Global J Pure Appl Sci 8: 203-208.

22. Buren JPV, Robinson WB (1969) Formation of complexes between protein and tannin acid. J Agri Food Chem 17: 772-777.

23. Funk DJ, Kumar A (2011) Antimicrobial Therapy for Life - threatening Infections Speed is Life Crit Care Clin 27: 53-76.

24. Jain A, Jain S, Rawat S (2010) Emerging fungal infections among children A review on its clinical manifestations, diagnosis, and prevention. J Pharm Bioallied Sci 2: 314-320

25. Bastos MLA, Lima MRF, Conserva LM, Andrade VS, Rocha EMM, et al. (2009) Studies on the antimicrobial activity and brine shrimp toxicity of Zeyheria tuberculosa (Vell.) Bur. (Bignoniaceae) extracts and their main constituents. Ann Clin Microbiol Antimicrob 8: 16

26. Rahman MM, Alexander IG, Gray Al, Khondkar P, Sarker SD (2008) Antibacterial and Antifungal Activities of the Constituents of Flemingia paniculata. Pharm Biol 46: 356-359.

27. Khan A, Rahman M, Islam MS (2010) Isolation and Bioactivity of a Xanthone Glycoside from Peperomia pellucid. Life Sci and Med Res 2010: 1-10.

28. Setshogo MP, Mbereki CM (2011) Floristiv diversity and uses of medicinal plants sold by street vendors in Gaborone, Botswana. African J Plant Sci Biotech 5: 69-74

29. McGaw LJ, Rabe T, Sparg SG, Jager AK, Eloff JN, et al. (2001) An investigation on the biological activity of Combretum species. J Ethnopharmacol 75: 45-50.

30. Breytenbach JC, Malan SF (1989) Pharmacochemical properties of Combretum zeyheri. S Afr J Sci 85: 372-374.

31. Masoko P, Eloff JN (2007) Screening of twenty-four South african Combretum and six Terminalia species (Combretaceae) for antioxidant activities. Afr $J$ Tradit Complement Altern Med 4: 231-239.

32. Aliyu AB, Musa AM, Abdullahi MS, Oyewale AO, Gwarzo US (2008) Activity of plant extracts used in northern Nigerian traditional medicine against methicillinresistant Staphylococcus aureus (MRSA). Niger J Pharm Sci 7: 1-8.

33. Cowan MM (1999) Plant products as Antimicrobial Agents. Clin Microbiol Rev 12: $564-582$.

34. Prasad R, Sharma M, Rawal MK (2011) Functionally Relevant Residues of 
Citation: Mangoyi R, Mafukidze W, Marobela K, Mukanganyama S (2012) Antifungal Activities and Preliminary Phytochemical Investigation of Combretum Species from Zimbabwe. J Microbial Biochem Technol 4: 037-044. doi:10.4172/1948-5948.1000069

Cdr1p: A Multidrug ABC Transporter of Human Pathogenic Candida albicans. $J$ Amino Acids 2011: 1-12.

35. Manoharlal R, Sharma M, Prasad R (2011) Molecular determinants of transien and reversible induced up-regulation of $C a C D R 1$ in azole susceptible clinical isolates of Candida albicans. Biosci Rep 31: 31-43.

36. Mukhopadhyay K, Prasad T, Saini P, Pucadyil TJ, Chattopadhyay A, et al. (2004) Membrane Sphingolipid-Ergosterol Interactions Are Important Determinants of Multidrug Resistance in Candida albicans. Antimicrob Agents Chemother 48: 1778-1787.

37. Zloh M, Kaatz GW, Gibbons S (2004) Inhibitors of multidrug resistance (MDR) have affinity for MDR substrates. Bioorg Med Chem Lett 14: 881-885.
38. Coldham NG, Webber M, Woodward MJ, Piddock LJ (2010) A 96-well plate fluorescence assay for assessment of cellular permeability and active efflux in Salmonella enterica serovar Typhimurium and Escherichia coli. J Antimicrob Chemother 65: 1655- 1663.

39. Rogers CB, Verotta L (1996) Chemistry and biological properties of the African Combretaceae. Chem Biol Pharmacol Prop Afric Med Plants pp 121-141.

40. Ruffo CK (1991) A survey of medicinal plants in Tabora Region, Tanzania. In Proceedings of International Conference on Traditional Medicinal Plants. 18-23 Feb, 1990, Arusha Tanzania pp.154-168.

\section{Submit your next manuscript and get advantages of OMICS} Group submissions

Unique features:

User friendly/feasible website-translation of your paper to 50 world's leading languages

Audio Version of published paper

Digital articles to share and explore

Special features:

200 Open Access Journals

15,000 editorial team

21 days rapid review process

Quality and quick editorial, review and publication processing

Indexing at PubMed (partial), Scopus, DOAJ, EBSCO, Index Copernicus and Google Scholar etc

Sharing Option: Social Networking Enabled

- Authors, Reviewers and Editors rewarded with online Scientific Credits

Better discount for your subsequent articles

Submit your manuscript at: http://www.editorialmanager.com/imb 